\section{International Scientific Journal Theoretical \& Applied Science}

\author{
p-ISSN: 2308-4944 (print) e-ISSN: 2409-0085 (online) \\ Year: 2017 Issue: $11 \quad$ Volume: 55 \\ Published: 28.11.2017 $\quad$ http://T-Science.org
}

Vladimir Nikolaevich Medvedev

The Teacher Department of Navigation,

The Engineer-mechanic,

State Maritime University Admiral Ushakov, Russia, medvedevsail@gmail.com

SECTION 21. Pedagogy. Psychology. Innovation in Education

\title{
YACHTING - CONDITIONS OF FORMING OF CONTROL PROFESSIONAL SKILLS OF STUDENTS OF SEA SPECIALTIES
}

Abstract: The basic principles of building an educational system of students engaged in yachting are considered; reveals the increasing role of students in yachting in the system of maritime vocational education and the lack of development of their practical organizations; analysis of the need for modern society in students with highly developed professional qualities and insufficient use of educational opportunities for yachting; shows the need to develop the professional qualities of students and the insufficiently developed scientific and methodological support of the basics of practical yachting.

Key words: forming of the personality, students, yachting, professional education, practical organization, naval fleet.

Language: Russian

Citation: Medvedev VN (2017) YACHTING - CONDITIONS OF FORMING OF CONTROL PROFESSIONAL SKILLS OF STUDENTS OF SEA SPECIALTIES. ISJ Theoretical \& Applied Science, 11 (55): 228-233.

Soi: http://s-0-i.org/1.1/TAS-11-55-29 Doi: crossef https://dx.doi.org/10.15863/TAS.2017.11.55.29

\section{УДК 372.851}

\section{ЯХТИНГ - УСЛОВИЯ ФОРМИРОВАНИЯ КОНТРОЛЬНЫХ ПРОФЕССИОНАЛЬНЫХ НАВЫКОВ СТУДЕНТОВ МОРСКИХ СПЕЦИАЛЬНОСТЕЙ}

Аннотация: Рассмотрены основные принципь построения воспитательной системы студентов, занимающихся яхтингом; раскрывается возрастающая роль занятий студентов яхтингом в системе морского профессионального образования и недостаточная разработанность их практических организаций; анализируется потребность современного общества в студентах с высокоразвитыми профессиональными качествами и недостаточное использовании воспитательньх возможностей занятий яхтингом; показывается необходимость развития профессиональных качеств студентов и недостаточная разработанность научно-методического обеспечения основ практических занятий яхтингом.

Ключевые слова: формирование личности, студенты, яхтинг, профессиональное образование, практическая организация, морской флот.

\section{Introduction}

В качестве результата предметной подготовки необходимо рассматривать уровень развития предметной компетентности студента составляющей его профессиональной компетентности, проявляющейся в готовности и способности в качестве основы продуктивной учебной, исследовательской и

профессиональной деятельности использовать фундаментальные предметные знания. Знания, умения и навыки, приобретённые студентами в рамках предметной подготовки обучения курсом общепрофессиональных дисциплин, необходимо оттачивать и применять на практике, для этого в программе обучения студентов плавательных специальностей и существует парусная морская практика.

\section{Materials and Methods}

Выявление усвоения учебного материала и овладение студентами требуемыми знаниями, умениями и навыками достигается в результате 
деятельности, которая образуется в ходе взаимодействия преподавателя (шкипера) и студента (матроса). Основными методами контроля знаний, умений и навыков студентов в яхтинге являются: устный опрос, практическая проверка, стандартизированный контроль. Значение этих методов заключается в том, чтобы наилучшим образом обеспечить своевременную и всестороннюю обратную связь между шкипером и матросами. Основываясь на обратную связь, шкипером устанавливается восприятие и усвоение учебного материала. Но также необходимо знать, что только комплексное применение методов контроля позволяет объективно выявлять динамику формирования системы знаний и умений студентов. Ни один из методов контроля в яхтинге не может сам по себе быть способным диагностировать все аспекты процесса обучения. Только правильное и педагогически целесообразное сочетание всех типов способствует повышению качества учебновоспитательного процесса. [8].

Эффективным условием формирования контрольных профессиональных навыков студентов в вузе могут быть занятия яхтингом при условии:

психолого-педагогической подготовленности преподавателей (шкиперов);

- отбором средств и методов педагогического воздействия на студентов;

- личностным отношением студентов к познавательной деятельности, их собственной активностью;

- насыщение программы подготовки студентов вузов дополнительными занятиями яхтингом;

- изменения характера содержания и организации учебных практик студентов плавательных специальностей морских вузов;

- поощрение студентов занимающихся яхтингом, принимающих участие в регатах различного уровня, занимающихся подготовкой яхт к навигации во время межсезонного периода.

Необходимо так построить учебновоспитательный процесс в вузе, который способствовал бы актуализации студентов к их профессиональной деятельности, развитию личности и побуждал бы их к профессиональному саморазвитию на этапе начального приобретения профессиональных навыков. [6,7].

Актуализация внутреннего мира студентов, определение ими личностной значимости и ценности занятий яхтингом стало возможным благодаря активным методам обучения. Дискуссии, круглые столы, тренинги, социальное проектирование способствовали активизации учебного процесса. Участие студентов в регатах, крейсерских походах, реализации социально-значимых проектов, подготовке и проведении мероприятий морской направленности дало возможность студентам приобрести специальные профессиональные навыки. Эти мероприятия позволили студентам повысить профессиональный и личностный опыт работы с различными категориями и типами людей, испытать технологии будущей работы [2,4].

Модель занятий студенческим яхтингом способствует развитию профессиональной деятельности будущих специалистов как плавательных, так и гуманитарных специальностей, стимулирует актуализацию их профессиональных навыков при соблюдении совокупности педагогических условий:

- содержания видов деятельности на палубе яхты осуществляется в соответствии с показателями готовности будущего специалиста к выполнению профессиональнотехнологической деятельности (готовность: к проектированию технологических процессов и производства; к организации и осуществлению производственно-технологической и инновационной деятельности; к рефлексии, самоконтролю и по его результатам коррекции производственно-технологической деятельности);

- формирование данной компетентности происходит по следующим этапам: информационный (решение задач на выделение искомых данных, уточнение формулировок задач, установление противоречий), процессуально-обучающий (соотнесение имеющихся знаний и готовности решать задачи; использование логико-поисковых задач, ориентированных на производственную деятельность инженера), деятельностный (умения выдвигать гипотезу, находить принципы решения, соотносить их с условиями задач, поставленных производственными проблемами и ситуациями) и обеспечивается применением многоуровневых задач и заданий профессиональной направленности;

создание профессионально

образовательной среды, способствующей развитию технологических навыков будущего специалиста, доминирующих в производственно-технологической

деятельности, достигается путем обогащения педагогических форм профессиональнотехнологическими задачами, характерными для общепрофессиональных дисциплин (изучение базы инженерной деятельности, принципов производственных процессов, теоретических основ устройства и работы оборудования). 
Разработана система критериев, с помощью которых можно оценить положительную динамику изменения знаний $\mathrm{y}$ студентов, занимающихся под парусами, убедиться в эффективности модели занятий студенческим яхтингом.

Контроль знаний и умений студентов один из важнейших элементов учебного процесса. От его правильной организации зависит эффективность управления учебновоспитательным процессом и качество подготовки студентов. Процесс обучения хождению под парусом не может быть полноценным без регулярной и объективной информации о том, как усваивается студентами материал, как они применяют полученные знания при работе с парусами и снастями на разных курсах относительно ветра при различной его силе. При этих взаимодействиях устанавливается «обратная связь», которая позволяет оценивать динамику усвоения учебного материала, действительный уровень владения системой знаний, умений, навыков. Анализируя эту систему, студенты и преподаватель могут взаимно вносить соответствующие коррективы в организацию учебного процесса (хождению на яхте под парусами). При этих условиях самоконтроль знаний и умений у студентов выполняет проверочную, обучающую, развивающую, воспитательную и методические функции одновременно, но наиболее важная и специфическая - проверочная функция. Показатели контроля служат главным основанием для суждения о результатах работы с парусами, т.е. для решения таких вопросов, как изменение курса относительно ветра, изменение настроек шкотов или стоячего такелажа, а также постановка и уборка парусов в данных погодных условиях. Данные контроля констатируют не только результаты и оценку учебной деятельности отдельных студентов, но и состояние учебно-воспитательной работы всего учебного взвода (группы), подсказывают меры, необходимые для ее совершенствования. Обучающая функция - другое важное предназначение контроля. В ходе выполнения контрольных заданий адресованных шкипером для студентов происходит повторение и закрепление, совершенствование приобретенных ранее знаний путем их уточнения и дополнения, студенты переосмысливают и обобщают пройденный материал, используют знания в практической деятельности. Контроль способствует формированию умений и навыков рационально организовывать учебную деятельность, самостоятельно овладевать знаниями. [1,11].
Развивающая функция контроля в яхтинге заключается в том, что он дает большие возможности для развития активности студента, формирования его практических навыков, знаний, умений и способностей. Контроль протекает в условиях обостренной работы внимания, памяти, мышления и процесса «самовспоминания». Студентам необходимо воспроизводить усвоенное, перерабатывать и систематизировать имеющиеся знания, делать выводы, обобщения, в практических условиях учиться применять теоретические знания, что эффективно содействует развитию обучаемого. Контроль знаний и умений решает и воспитательную функцию, т.к. он всегда глубоко затрагивает эмоциональную сферу личности. Результаты сугубо индивидуальных усилий по усвоению учебного материала становятся предметом общественного суждения. Правильно осуществляя контроль, преподаватель имеет возможность постоянно побуждать студентов к совершенствованию своих знаний и умений, к выработке объективных самооценочных суждений, к развитию потребности в самоконтроле. Контроль знаний и умений выполняет методическую функцию. Его процесс и результаты очень важны для совершенствования работы самого преподавателя. Контроль позволяет оценить методы преподавания, увидеть его сильные и слабые стороны, выбрать оптимальные варианты обучающей деятельности. [14,15].

Контроль дает необходимый учебный и воспитательный эффект при соблюдении ряда требований. Он должен быть: планомерным и систематическим, т.е. осуществляться в соответствии с запланированным ходом учебновоспитательного процесса, составлять его органическую часть и строиться на основных вопросах программы обучения. Это требует непрерывного изучения уровня овладения студентами системой знаний, умений и навыков. Регулярность самоконтроля позволяет своевременно выявлять и исправлять ошибки, недоработки, принимать меры к их устранению путем соответствующего совершенствования учебного процесса. Объективность проверки определяется многими факторами: научной обоснованностью и разработанностью целей и содержания обучения, требований к знаниям, умениям и навыкам учащихся, соответствием содержания проверочных заданий целям проверки.

Контроль всесторонний, т.е. наиболее полно выявляющий фактический уровень усвоения студентами учебной информации, охватывающий все разделы программы, обеспечивающий проверку не только предметных знаний, но и усвоение 
мировоззренческих идей, общеучебных и специальных умений и навыков. Контроль не должен ограничиваться только выявлением того, что знают и умеют студенты, но и могут ли пользоваться этой информацией для решения учебных и практических задач. В этом случае контроль обеспечит проверку содержания формируемой у студентов профессиональной деятельности (уровень сформированности основ этой деятельности). Контроль индивидуальный - процесс овладения знаниями и умениями. Каждый студент овладевает знаниями и умениями в соответствии со своими внутренними психологофизиологическими особенностями. Ко всем студентам необходимо предъявлять одинаковые требования в отношении объема знаний, уровня сформированности умений, но иногда необходимо принимать во внимание такие индивидуальные качества студентов, как природную медлительность, робость, застенчивость, излишнюю самоуверенность, физические недостатки. [12].

Контроль должен быть педагогически тактичным - осуществляться в спокойной деловой обстановке. Не следует торопить студентов с действием или переключать их на другой процесс в ходе выполнения конкретноуказанного самим же преподавателем действия. Все замечания, указания и оценку деятельности студента необходимо делать в тактичной и доброжелательной форме. Деятельность выступает не особым абстрактным учебным предметом, а как форма и способ усвоения предмета любой конкретной учебной дисциплины, при этом она и сама усваивается. Действие в яхтинге основополагающий процесс. Морская среда сама по себе очень динамична, это в равной мере переносится и на палубу парусной яхты. Ветер от природы «живой» часто меняет направление и силу в единицу времени. Паруса зависимы от силы и направления работы ветра: не смог подстроиться под его изменение - паруса не будут иметь определенной тянущей силы, а это означает увеличение влияния дрейфа вместо движения вперёд с большей скоростью. Соответственно увеличивается пройденное расстояние и время на прохождение дистанции. Студенты учатся правильно ориентироваться в ситуации, требующей действия, и правильно ориентировать его исполнение - самое важное в жизни. [3].

Занятия яхтингом в вузе должны помочь студентам освоить эффективные средства управления учебной деятельностью, а именно:

- в сотрудничестве с преподавателем ставить новые учебные задачи;
- преобразовывать практическую задачу в познавательную;

- проявлять познавательную инициативу в учебном сотрудничестве;

- самостоятельно учитывать выделенные преподавателем ориентиры действия;

- осуществлять констатирующий контроль по результату и по способу действия, актуальный контроль на уровне произвольного внимания;

- самостоятельно адекватно оценивать правильность выполнения действия и вносить необходимые коррективы в исполнение, как по ходу его реализации, так и в конце действия. [9].

Успешность решения данных задач во многом зависит от того, как устроена система контроля и оценки в образовательном процессе: насколько она поддерживает и стимулирует учащихся; насколько точную обратную связь она обеспечивает; насколько включает студентов в самостоятельную контрольнооценочную деятельность; насколько она информативна для управления процессом обучения. В теории образовательных систем контроль рассматривается как операция сопоставления запланированного результата с эталонными требованиями и стандартами, а оценка - как сопоставление полученного результата с поставленной целью по заранее установленным критериям. В то же время результат любой деятельности, в том числе учебной, требует осмысления, сравнения, оценки исходных и конечных состояний, для студента это осмысление должно выражаться следующими вопросами: «Достигнута ли учебная цель?», «Если нет, то почему и какова тогда степень частичного достижения цели?», «Если результаты превзошли поставленную цель - то почему и в какой степени?», «Удалось ли реализовать все задачи, составляющие в совокупности поставленную цель?», «Какие задачи оказались нерешенными и почему?», «Что необходимо усовершенствовать, чтобы их все же решить?», «Какой опыт приобретен в процессе достижения учебной цели, и как он может быть полезен в дальнейшем?» и так далее. Научить студентов каждый раз ставить подобные вопросы и отвечать на них крайне важно. Поэтому, без изменения подходов к системе контроля и оценки в процессе обучения невозможно достичь поставленных образовательных целей перед яхтингом. [5].

Система контроля и оценки не может ограничиваться только проверкой усвоения знаний и выработки умений и навыков. Здесь видна более важная социальная задача: развить у студентов умение контролировать, прежде всего - самого себя, критически оценивать свою 
деятельность, находить ошибки, пути их устранения, определять границу своих знаний. Действие оценки - это действие, благодаря которому человек оценивает свои возможности действовать, определяет, достаточно ли у него знаний для решения новой задачи и каких именно знаний ему недостаёт.

\section{Conclusion}

Включая в педагогический процесс занятия яхтингом на факультативной основе, мы создаем развивающую среду, которая помогает студентам освоить новые способы поведения, расширить свои профессиональные знания и навыки, найти им практическое применение. Яхтинг также развивает продуктивное творческое мышление, коммуникативную компетентность. Участие студентов в крейсерских походах и различных «морских» проектах помогает им приобрести опыт, связанный с организацией коллективной творческой деятельности. Это даёт возможность студентам развить свои профессиональные навыки и личностный опыт, апробировать технологии будущей работы в должности офицера морского флота. Проведенная работа подтверждает, что изменение характера содержания и организации учебных практик студентов углубляет и расширяет их знания в области технологии общения с различными типами личности и характера сверстников, способствует приобретению и развитию нового субъектного опыта профессиональной деятельности. [10,13].

Исследование не претендует на окончательное решение проблемы поиска путей и средств, способствующих личностному развитию студентов, но актуализирует проблему подготовки специалиста, используя для этого peсурс занятий яхтингом в вузе. Дальнейшее углубленное исследование данной проблемы может осуществляться в направлении изучения влияния яхтинга на студентов, обучающихся специальностям гуманитарного профиля. [16].

Возможен научный поиск, направленный на разработку проблемы воспитания абитуриентов, студенческой молодежи средних и специальных учебных заведений, а также учащихся профтехобразования по вовлечению их в занятия яхтингом, формированию у них активной гражданской позиции, любви к своему учебному заведению, к своей стране. [17,18].

\section{References:}

1. A.N. Leontev (1975) Deyatelnost. Soznanie. Lichnost. M.: Politizdat.

2. L.S. Vygotskij (1934) Myshhlenie i rech. M.L.: Socekgiz.

3. P.Ya. Galperin (1999) Vvedenie v psixologiyu. M.: Knizhnyj dom «Universitet».

4. Z.A. Reshetova (1985) Psixologicheskie osnovy professionalnogo obucheniya. M.: Iz-vo MGU.

5. Z.A. Reshetova (2002) Formirovanie sistemnogo myshleniya $\mathrm{v}$ obuchenii. teoreticheskie osnovy // Formirovanie sistemnogo myshleniya $\mathrm{v}$ obuchenii : uchebnik dlya vuzov / pod red. Z.A. Reshetovoj. - M.: Yuniti-Dana.

6. Z.A. Reshetova (2013) K voprosu o mexanizmax usvoeniya i razvitiya. Nacionalnyj psixologicheskij zhurnal №1(9)/2013, 25-32. doi: 2079-6617/2013.0104

7. N.F.Talyzina (1998) Pedagogicheskaya psixologiya. M.: Akademiya.

8. V.V. Davydov (1992) Psixologicheskaya teoriya uchebnoj deyatelnosti i metodov nachalnogo obucheniya, osnovannyx na soderzhatelnom obobshhenii. T.: Peleng.
9. I.I. Ilyasov (1981) Organizaciya sovmestnoj raboty studentov. (v soavt.). Moscow.

10. O.K. Tixomirov (1975) Psixologicheskie issledovaniya tvorcheskoj lichnosti. M.: Nauka.

11. A.G. Asmolov (1984) Lichnost kak predmet psixologicheskogo issledovaniya. M.: Iz-vo MGU.

12. Yu.A. Samonenko (2001) Psixologiya i pedagogika. M.: Yuniti-Dana.

13. Mishchik SA (2015) Pedagogometrik - science and academic subject. Materialy Mezhdunarodnoy nauchnoy konferenctsii "European Technology in Science" 28.02.2015. ISJ Theoretical \& Applied Science 02 (22): 103-106 Malmö, Sweden. doi: http://dx.doi.org/10.15863/TAS.2015.02.22.17

14. V.N. Medvedev (2017) Yachting - is the factor of development of social activity of students. Isj theoretical \& applied science, 06 (50): 133-138. doi:

https://dx.doi.org/10.15863/TAS.2017.06.50.18

15. V.N. Medvedev (2017) Yachting - the condition of forming of the identity of the student. ISJ Theoretical \& Applied Science, 07 


\begin{tabular}{l|lrl|l|ll} 
& ISRA (India) & $=\mathbf{1 . 3 4 4}$ & SIS (USA) & $=\mathbf{0 . 9 1 2}$ & ICV (Poland) & $=\mathbf{6 . 6 3 0}$ \\
Impact Factor: & ISI (Dubai, UAE) $=\mathbf{0 . 8 2 9}$ & PUHL (Russia) $=\mathbf{0 . 2 0 7}$ & PIF (India) & $=\mathbf{1 . 9 4 0}$ \\
& GIF (Australia) & $\mathbf{0 . 5 6 4}$ & ESJI (KZ) & $=3.860$ & IBI (India) & $=\mathbf{4 . 2 6 0}$ \\
& JIF & $\mathbf{1 . 5 0 0}$ & SJIF (Morocco) & $=\mathbf{2 . 0 3 1}$ & & \\
\hline
\end{tabular}

(51):

$117-122$.

doi:

https://dx.doi.org/10.15863/TAS.2017.07.51.20

16. V.N. Medvedev (2017) Yachting - development of the generalized professional activity of students. ISJ Theoretical \& Applied Science, 08 (52):

108-114.doi: https://dx.doi.org/10.15863/TAS.2017.08.52.17

17. V.N. Medvedev (2017) Yachting - conditions of forming of special technology skills of students of sea higher educational institutions. ISJ
Theoretical \& Applied Science, 09 (53): 171176.

doi:

https://dx.doi.org/10.15863/TAS.2017.09.53.26

18. V.N. Medvedev (2017) Yachting development of the subject relations of professional skills of students. ISJ Theoretical \& Applied Science, 10 (54): 166 - 170. doi: https://dx.doi.org/10.15863/TAS.2017.10.54.27 